\title{
Barras de Cereal como Matriz Sólida para la Incorporación de Microorganismos Probióticos
}

\author{
Liliana Serna-Cock ${ }^{(1)^{*}}$, Jorge E. Angulo-López ${ }^{(2)}$, y Alfredo A. Ayala-Aponte ${ }^{(3)}$ \\ $(1,2)$ Facultad de Ingeniería y Administración, Universidad Nacional de Colombia-Sede Palmira. Carrera 32 \\ \# 12-00, Chapinero, Vía Candelaria, Palmira-Valle del Cauca, Colombia. (e-mail: Iserna@unal.edu.co; \\ jeangulol@unal.edu.co) \\ (3) Escuela de Ingeniería de Alimentos, Universidad del Valle, calle 13 \#100-00, Colombia \\ (e-mail: alfredo.ayala@correounivalle.edu.co)
}

Recibido Jul. 14, 2014; Aceptado Sep. 23, 2014; Versión final recibida Oct. 18, 2014

\begin{abstract}
Resumen
Se evaluaron barras de cereal, como matriz sólida, para la incorporación de un microorganismo probiótico. Se midió la aceptabilidad, perfil de sabor, perfil de textura y el aporte nutricional durante el proceso de elaboración de la barra de cereal. Se utilizó la bacteria ácido láctica Weissella confusa. La aceptabilidad del producto en cuanto a sabor, color, olor y textura fue superior al $50 \%$. El perfil de sabor indicó que los sabores a arroz soplado, dulce y uvas pasas fueron más acentuados, y no se percibió sabor a rancio. Las formulaciones mostraron carácter prebiótico $(5.91 \%$ en base seca de fibra dietaria). La bacteria probiótica disminuyó su viabilidad de $3.73 \times 10^{11}$ a $5.62 \times 10^{7} \mathrm{UFC} / \mathrm{g}$. Sin embargo, el recuento se encontró dentro del rango para ser considerado producto probiótico. Los resultados demostraron que la barra de cereal puede emplearse como matriz sólida para el desarrollo de formulaciones sinérgicas probióticas y prebióticas.
\end{abstract}

Palabras clave: cereales, probióticos, prebiótico, fibra, Weissella confusa

\section{Cereal Bars as Solid Matrix for the Incorporation of Probiotics Microorganisms}

\begin{abstract}
Cereal bars as solid matrix for the incorporation of a probiotic microorganism were evaluated. The acceptability, flavor profile, texture profile and nutritional value were evaluated. The lactic acid bacterium Weissella confusa was used. Product acceptability in terms of taste, color, odor and texture was over $50 \%$. The flavor profile indicated, that puffed rice, sweet, and raisins flavors were more pronounced, and rancid flavor was not perceived. The formulations were prebiotic $(5.91 \%$ on dry basis of dietary fiber). Viability of probiotic bacteria decreased from $3.73 \times 10^{11}$ to $5.62 \times 10^{7} \mathrm{CFU} / \mathrm{g}$. However, the count was within a range in which the product can be considered as probiotic. The results showed that cereal bars can be used as solid matrix for the development of probiotic and prebiotic synergistic formulations.
\end{abstract}

Keywords: cereal, probiotics, prebiotics, fiber, Weissella confusa 


\section{INTRODUCCION}

La selección de matrices alimentarias y el potencial sinérgico de los alimentos, son factores que se deben considerar en el desarrollo de alimentos probióticos, de no tenerse en cuenta estos factores, se puede reducir la eficacia funcional de los alimentos (Ranadheera et al., 2010). En el diseño de productos probióticos la combinación apropiada de prebióticos y probióticos produce mayor beneficio al consumidor y puede producir un efecto sinérgico (Tripathi y Giri, 2014). Se ha reportado que las mejores matrices para las bacterias probióticas son productos lácteos fermentados (Rivera-Espinoza y Gallardo-Navarro, 2010), sin embargo, los productos lácteos probióticos requieren de almacenamiento y transporte en frío, lo que representa costos agregados para el producto (Ouwehand et al., 2004). Se suman a éstas limitaciones, el contenido de colesterol y de lactosa que presentan algunos productos lácteos probióticos, lo cual los hace inadecuados para consumidores hipercolesterolémicos y/o intolerantes a la lactosa (Ranadheera et al., 2010). La inclusión de probióticos en matrices sólidas tiene ventajas (Ouwehand et al., 2004), por lo cual se están comercializando productos probióticos en matrices sólidas no lácteas, en forma de pellets, cápsulas y liofilizados (Ranadheera et al., 2010 y Rivera-Espinoza et al., 2010).

Otros aspectos importantes en el desarrollo de probióticos en matrices sólidas son la aceptabilidad sensorial y la viabilidad del microorganismo probiótico dentro de la matriz alimentaria (Jankovic et al., 2010). Los granos de cereales son matrices secas que se pueden considerar para el desarrollo de probióticos, ya que pueden estimular selectivamente el crecimiento de lactobacilos y bifidobacterias presentes en el colon (Andersson et al., 2001; Charalampopoulos et al., 2002). Las barras de cereal han ganado aceptación entre los consumidores debido a que son una alternativa sana de obtención de energía y constituyen un perfil nutricional equilibrado (Ryland et al., 2010). Se definen como productos procesados, obtenidos a partir de la mezcla y aglutinación de un conjunto de cereales básicos y frutos secos (Ferreyra et al., 2009). Según Ouwehand et al. (2004), las barras de cereal constituyen una excelente matriz para desarrollar productos probióticos y prebióticos.

De otro lado, muchos microorganismos se han utilizado en el desarrollo de alimentos probióticos, sin embargo la bacteria ácido láctica Weissella confusa, a pesar de haber demostrado actividad antimicrobiana contra patógenos como Staphylococcus aureus, Streptococcus agalactiae, Klebsiella neumoni, no ha sido evaluada en la elaboración de productos probióticos (Serna et al., 2010; Funmilola et al., 2011). El objetivo de este trabajo fue evaluar barras de cereal, como matriz sólida, para la incorporación de un microorganismo probiótico (Weissella confusa), medir su aceptabilidad en cuanto a sabor, color, olor y textura, cuantificar su aporte nutricional, y determinar la viabilidad del probiótico durante su proceso de elaboración.

\section{METODOLOGÍA}

Para una mejor presentación la metodología se detalla en seis subsecciones: i) reproducción de la cepa probiótica e incorporación del probiótico en un vehículo; ii) producción de barras de cereal e incorporación del probiótico; iii) estudio de aceptabilidad general perfil de sabor y textura; iv) caracterización de barras de cereal probióticas; v) medición de la viabilidad del probiótico; vi) y análisis estadístico

\section{Reproducción de la cepa probiótica e incorporación del probiótico en un vehículo}

Se utilizó la bacteria ácido láctica Weissella confusa crioconservada en glicerol, la cual ha demostrado tener actividad antimicrobiana contra Gram (+) y Gram (-) como Staphylococcus, Streptococcus, Klebsiella y E. coli (Serna y Enríquez, 2013). Para obtener la biomasa probiótica necesaria para formular barras de cereales, se realizaron 3 fermentaciones en discontinuo utilizando en cada fermentación $550 \mathrm{ml}$ de sustrato comercial puro MRS (SC) (De Man et al., 1960), el cual provee las exigencias nutricionales de esta bacteria ácido láctica. Las fermentaciones se realizaron en erlenmeyer de $1000 \mathrm{ml}$, los cuales permanecieron agitados elipsoidalmente, a $120 \mathrm{rpm}$ por 4 horas a $33^{\circ} \mathrm{C}$ (equipo VWR Incubating Orbital Shaker VWR model 5000I, USA), El pH se ajustó a 6.0 utilizando una solución $\mathrm{NaOH} 1 \mathrm{M}$.

Concluidas las fermentaciones se separó la biomasa de los metabolitos producidos durante la fermentación. El fermentado se envasó en tubos falcon de $50 \mathrm{ml}$ los cuales se centrifugaron por 30 min a 2860xg (Eppendorf Centrifuge-5804R, Germany). Posteriormente se separó la biomasa (precipitado) del sobrenadante, por decantación. La biomasa se lavó utilizando $1 \mathrm{ml}$ de $\mathrm{NaCl}$ al $0.9 \%$, con el objetivo de dejar las células probióticas libres de metabolitos. La biomasa se liofilizó (Labconco, Freezone 6 litros, USA) utilizando congelación a $-20^{\circ} \mathrm{C}$, presión de vacío de $0,120 \mathrm{mBar}$, y temperatura en el condensador de $50^{\circ} \mathrm{C}$. 
La biomasa liofilizada se incorporó en un vehículo y posteriormente el vehículo se adicionó a las barras de cereal. Como vehículo del probiótico se utilizó cobertura blanca sabor a chocolate (corona repostería, Compañía Nacional de chocolate). Este vehículo se utilizó ya que estudios de mercado han demostrado que el sabor a chocolate tiene gran aceptación por parte de los consumidores (FAO/WHO, 2009). La cobertura se fundió a $32^{\circ} \mathrm{C}$ y se adicionó la biomasa liofilizada. La bacteria probiótica se incorporó a la cobertura blanca de tal manera, que cada barra presentara características de probiótico, es decir contenidos de probiótico de $10^{6}$ a $10^{9}$ microorganismos gramo de barra-1. La Incorporación del probiótico durante la elaboración de la barra no se consideró, ya que daría lugar a pérdidas de viabilidad ocasionada por el uso de altas temperaturas en el momento del horneado (Santivarangkna, et al., 2006; citado por Tripathi y Giri, 2014).

\section{Producción de Barras de Cereal e incorporación del probiótico}

Con el fin de determinar una relación cereal-aglutinante de alta aceptación sensorial, se realizaron cuatro formulaciones de barras de cereal (Tabla1), siguiendo los métodos utilizados por Sun-Waterhouse et al., (2010) y Dutcosky et al., (2006). Los cereales y aglutinantes se consiguieron en el mercado nacional. La adición de sal se realizó para potencializar los sabores y para favorecer la conservación. Los cereales se pesaron (Balanza de precisión, Denver Instrument APX-323, USA), se mezclaron, se distribuyeron sobre una bandeja de acero inoxidable, y se llevaron al horno a $130^{\circ} \mathrm{C}$, durante $10 \mathrm{~min}$, con el objetivo de disminuir su contenido de agua.

Los aglutinantes (Tabla 1) se pesaron y fueron puestos en un recipiente con recubrimiento anti-adherente a fuego lento, en agitación constante hasta alcanzar el punto de ebullición. El jarabe se adicionó a los cereales, hasta homogenizar todos los componentes. La mezcla se llevó a una bandeja de acero inoxidable, y se horneo a temperatura de $130^{\circ} \mathrm{C}$ por 15 minutos. Posteriormente, las barras horneadas se dejaron en reposo a $25^{\circ} \mathrm{C}$ y se procedió a cortar las barras de cereal en medidas de $45 \mathrm{~mm}$ x $95 \mathrm{~mm}$ x $12 \mathrm{~mm}$, peso promedio de $20,94 \mathrm{~g}$.

Tabla 1. Formulaciones de barras de cereal. A: Formulación Base (61.4-38.6\%), B: (50-50 \%), C: (40-60\%), D: (55-45\%). El porcentaje corresponde a la relación cereal-aglutinante respectivamente.

\begin{tabular}{|c|c|c|c|c|c|}
\hline \multicolumn{2}{|r|}{ Formulaciones } & \multicolumn{4}{|c|}{ Porcentaje (\%) } \\
\hline & Material & $A$ & B & C & $\mathrm{D}$ \\
\hline \multirow{7}{*}{ 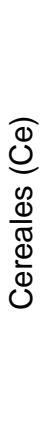 } & Avena en Hojuelas & 12 & 6 & 4,8 & 6,6 \\
\hline & Cebada en Hojuelas & 10 & 7 & 5,6 & 7,7 \\
\hline & Arroz Soplado & 15 & 10 & 8 & 16,5 \\
\hline & Maíz en Hojuelas & 5 & 15 & 12 & 11 \\
\hline & Nueces del Brasil & 7,4 & 3 & 2,4 & 3,3 \\
\hline & Maní & 6 & 3 & 2,4 & 3,3 \\
\hline & Uvas pasas & 6 & 6 & 4,8 & 6,6 \\
\hline \multirow{6}{*}{ 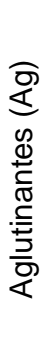 } & Miel & 16 & 14 & 16,8 & 12,6 \\
\hline & Jarabe de Glucosa & 9 & 13 & 15,6 & 11,7 \\
\hline & Aceite Vegetal & 5,6 & 6 & 7,2 & 5,4 \\
\hline & Maltodextrina & 6 & 11,8 & 14,16 & 10,62 \\
\hline & Lecitina de Soya & 2 & 5 & 6 & 4,5 \\
\hline & Sal & 0 & 0,2 & 0,24 & 0,18 \\
\hline
\end{tabular}

A las barras cortadas y horneadas se les adicionó el probiótico vehiculizado en la cubierta blanca, descrita arriba. La cobertura se esparció sobre una cara de las barras, teniendo en cuenta que el cereal representara el $87,26 \%$ y el vehículo el $12,74 \%$, así todas las barras sin importar su peso tendrían la misma cantidad de UFC/g. Una vez solidificada la cobertura sobre la barra de cereal, se empacaron individualmente en bolsas de colamidado de polipropileno con aluminio (transmisión de vapor de agua de 0,62 g/m²/24h/atm). 


\section{Estudio de Aceptabilidad general Perfil de Sabor y Textura}

A las cuatro formulaciones se les realizó prueba de aceptabilidad general. Las muestras fueron identificadas con códigos numéricos y se presentaron en forma aleatoria, en porciones de $7 \mathrm{~g}$, a 14 panelistas consumidores en edades entre 19 y 45 años (Ferreyra, 2009; Olivera et al., 2012). El panel fue semientrenado con anterioridad, dándoles a consumir barras de cereal 1 vez por semana, durante 4 semanas. La aceptabilidad general se determinó mediante escala hedónica de cinco puntos (me gusta muchísimo, me gusta mucho, me gusta un poco, me disgusta un poco, me disgusta muchísimo) (Freitas y Moretti, 2006).

A la formulación que presentó mayor aceptabilidad general se le realizó perfil de sabor y de textura. En el perfil de sabor se evaluaron cada uno de los ingredientes de las barras de cereal y la evaluación se hizo mediante una escala de cinco puntos, dónde la codificación estaba expresada en intensidad de percepción del gusto, así: $5=$ Extrema; $4=$ grande; $3=$ media; $2=$ ligera; 1 = casi imperceptible; $0=$ ausencia total. En el perfil de textura se midió dureza, fracturabilidad y adhesividad utilizando la misma escala cualitativa de valoración, descrita en perfil de sabor. La dureza se midió como la fuerza requerida para comprimir la barra de cereal entre los molares. La fracturabilidad se midió como la fuerza a la que el material se fractura entre los molares. La adhesividad se evaluó como el trabajo necesario para retirar el producto de la superficie (molares o paladar) durante su consumo.

\section{Caracterización de barras de cereal probióticas}

Las barras probióticas obtenidas con la formulación de mayor aceptación en cuanto a sabor, color, olor y textura, se caracterizaron en cuanto a su contenido en materia seca, humedad, actividad de agua, proteína, extracto etéreo, cenizas, contenido de fibra, azúcares totales y energía bruta.

La materia seca y humedad se determinaron acorde al método estándar de la AOAC $(934,01,1990)$. La actividad de agua se evaluó a $28^{\circ} \mathrm{C}$ en un medidor de actividad de agua (AquaLab Series 4TEDUO, Decagon Devices Inc.). El contenido de nitrógeno se cuantificó mediante el método Kjeldahl (Kjeldah, 1883) y se utilizó un factor de 6.25 para el cálculo del contenido de proteína. El extracto etéreo se determinó acorde al método estándar de la AOAC (942.05), se utilizó un equipo Soxhlet (Soxhlet S6-E2, Colombia) con éter de petróleo grado reactivo como disolvente. Las cenizas se determinaron acorde al método estándar de la AOAC (942,05), en una mufla (Select-Horn) a $600^{\circ} \mathrm{C}$ por 6 horas (AOAC, 1990). El contenido de fibra se determinó por el método de Van Soest et al. (1991), y se realizó la discriminación de sus componentes: hemicelulosa, celulosa y lignina presente en el material. La fibra dietaria se determinó según el método AOAC 991.43. Los carbohidratos totales (CHOt) fueron obtenidos por la ecuación 1.

$\mathrm{CHOt}=100-(\% \mathrm{~PB}+\% \mathrm{EE}+\% \mathrm{MI})$

En esta ecuación, PB es el contenido de proteína bruta, EE es el extracto etéreo y $\mathrm{Ml}$ es el contenido de cenizas. La energía bruta se determinó por combustión del material en una bomba calorimétrica con oxígeno a $30 \mathrm{~atm}$.

\section{Medición de la Viabilidad del probiótico}

La viabilidad del probiótico se midió en cuatro momentos del proceso de elaboración de las barras de cereal, una vez concluidas las fermentaciones (cuarta hora de fermentación), inmediatamente después del lavado de las células probióticas, posterior a la liofilización, e inmediatamente después de incorporados a la barra de cereal (en el medio vehiculizante). Para la evaluación de la viabilidad, se realizó recuento en placa de células viables (UFC/ml) mediante siembra en agar MRS (De Man et al., 1960). Se realizaron diluciones decimales desde $10^{-1}$ hasta $10^{-9}$ empleando agua peptona al $0,1 \%$. Las placas se incubaron a $32^{\circ} \mathrm{C}$ durante 24 horas. Finalizado el tiempo de incubación, se procedió a contar las cajas que contenían entre 30 y 300 colonias. Las pruebas de viabilidad se realizarán por triplicado. Los resultados se expresaron como UFC/g.

\section{Análisis Estadístico}

Para la evaluación del color, forma, olor, sabor y textura se utilizó un panel semi-entrenado, el cual estuvo conformado por 10 jueces (siete hombres y tres mujeres), quienes utilizaron una escala apreciación de 1-5 puntos. Como técnica de análisis se utilizó la Prueba de Friedman, la cual como prueba no paramétrica es equivalente a un análisis de varianza. Por ser una prueba no paramétrica, la Prueba de Friedman no se fundamenta en el cumplimiento de supuestos de tipo estadístico. Para analizar el efecto del procesamiento sobre la viabilidad del probiótico se utilizó un diseño unifactorial con 4 niveles, utilizando como factor momento del proceso de elaboración, y como niveles i) concluida la fermentación, ii) posterior al lavado de las células, iii) posterior a la liofilización, iv) una vez incorporadas a las barras de cereal. 


\section{RESULTADOS Y DISCUSIÓN}

Los resultados y discusión se presentan en tres subsecciones: i) formulación de la barra de cereal, ii) caracterización física y química de las barras de cereal con formulación D; y iii) estudio de aceptabilidad perfil de sabor y textura de la formulación $\mathrm{D}$

\section{Formulación de la Barra de Cereal}

Mediante los resultados del análisis estadístico se pudo establecer entre las formulaciones $A, B, C$ y $D$, cual fue la mejor formulación. Se presentaron diferencias estadísticamente significativas en las variables de olor, sabor y textura. Sin embargo, no se presentaron diferencias estadísticamente significativas entre las formulaciones en cuanto a color y forma. (Tabla 2). Siendo la formulación D (Figura 1), la que presentó los niveles más altos de aceptabilidad, de acuerdo a la escala presentada. (Nivel 1 que corresponde a me gusta muchísimo hasta el nivel 5 que corresponde a me disgusta muchísimo).

Tabla 2: Rango de promedios entre formulaciones

\begin{tabular}{|l|l|l|l|l|l|}
\hline Formulación & Olor & Color & Forma & Sabor & Textura \\
\hline A & 3.6 & 2.45 & 2.6 & 2.2 & 3.55 \\
\hline B & 3.15 & 2.45 & 2.25 & 3.55 & 3 \\
\hline C & 1.6 & 2.65 & 2.6 & 2.85 & 1.85 \\
\hline D & 1.65 & 2.45 & 2.55 & 1.4 & 1.6 \\
\hline Sig. Asintót. & $<0.05$ & $>0.962$ & $>0.844$ & $<0.001$ & $<0.05$ \\
\hline
\end{tabular}

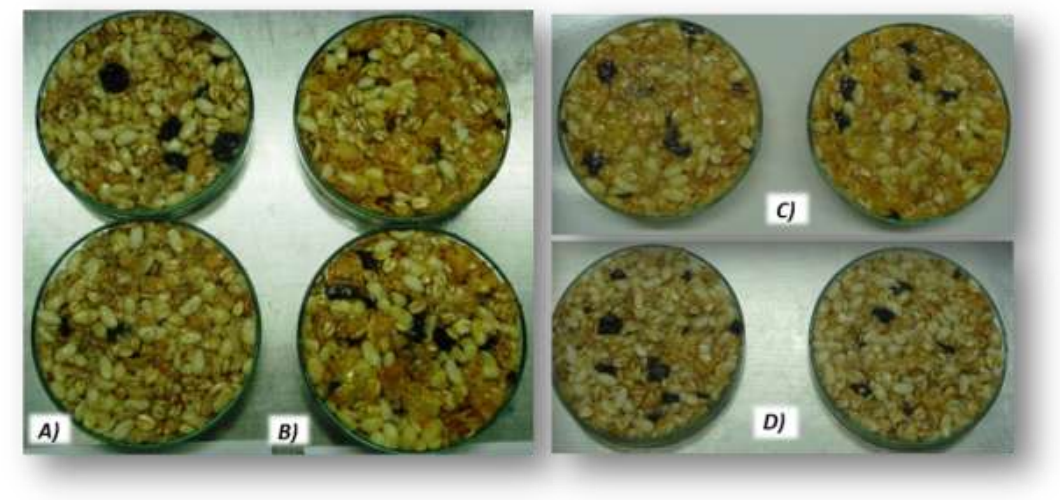

Fig. 1: Ensayos previos A) 61.4-38.6\%, B) (50-50) \%, C) (40-60) \%, D) (55-45) \%, relación Cereales-Aglutinantes respectivamente.

\section{Caracterización física y química de las barras de cereal con formulación $D$}

Los componentes mayoritarios de las barras de cereal de la formulación $\mathrm{D}$ fueron carbohidratos, extracto etéreo, y fibra dietaria total (FDT). El contenido de FDT, de fibra dietética Insoluble (FDI) y fibra dietética soluble (FDS) fueron valores superiores a los reportados por Freitas y Moretti (2006), y Olivera, M et al (2012), (Tabla 3).

Según la comisión Europea, para que un alimento sea considerado como "fuente de fibra" debe tener al menos $3 \mathrm{~g}$ de fibra por $100 \mathrm{~g}$, y para que se considerado como "alto en fibra" debe tener $6 \mathrm{~g}$ de fibra por 100 $\mathrm{g}$ (European commission, 2006), por lo tanto, la barra de cereal que presentó mayor aceptación sensorial es indudablemente un alimento funcional. Ha sido suficientemente estudiada la asociación que existe entre consumo de fibra y protección de cáncer de colon (Sánchez et al., 2013), disminución en la absorción intestinal del colesterol (Elleuch et al., 2011) y desintoxicación (debido a la capacidad de la fibra para unirse a metales pesados) (Nawirska, 2005).

El porcentaje de proteína fue de $5.85 \%$, el cual se encuentra ligeramente por encima del rango, de aporte proteico de la mayoría de los productos comerciales que se encuentran en el mercado (4,4 -5.5\%). El contenido de materia grasa presentado fue satisfactorio $(16.7 \%)$ en comparación con los productos convencionales, que presentan valores entre 4 y $12 \%$.(Freitas y Moretti, 2006). El porcentaje de actividad de agua y humedad relativa iniciales fueron de 0.38 y $6.87 \%$ respectivamente, valores inferiores a los reportados por Freitas y Moretti, (2005) quienes indicaron valores de $8.59 \%$ para humedad relativa y 0.63 
para actividad de agua. Obtener valores bajos en estas variables es un factor importante ya que conlleva a prolongar la vida útil de los alimentos; así mismo, ambos valores estuvieron dentro de los parámetros establecidos para este tipo de productos (máx. 12\%HR y $\geq 0.6 \mathrm{Aw}$ ) (Vesterlund et al., 2012).

Tabla 3. Análisis proximal de barras de cereal (formulación D) y comparación con otros autores.

\begin{tabular}{|l|c|c|c|}
\hline \multicolumn{1}{|c|}{ Determinación (\%)*bs } & Formulación D & Freitas y Moretti. 2006 & Olivera. M et al. 2012 \\
\hline Materia Seca & 93.13 & & 1.46 \\
\hline Cenizas (BS) & 2 & 2.2 & 15.7 \\
\hline Proteína (BS) & 5.83 & 15.31 & 12.6 \\
\hline Extracto Etéreo(BS) & 16.7 & 5.64 & 57 \\
\hline Carbohidratos(BS) & 71.14 & 60.97 & \\
\hline FDN (BS) & 4.33 & & \\
\hline FDA (BS) & 1.77 & & \\
\hline LDA (BS) & 0.74 & & 3.4 \\
\hline Hemicelulosa (BS) & 2.56 & & \\
\hline Celulosa (BS) & 1.03 & & \\
\hline Fibra Dietética Total (FDT) & 5.9142 & & \\
\hline Fibra Dietética Insoluble (FDI) & 4.1951 & 5.17 & \\
\hline Fibra Dietética Soluble (FDS) & 1.7191 & 4.3 & \\
\hline Energía Bruta (Kcal) & 103.06 & 0.87 & \\
\hline Actividad de Agua & 0.38 & & \\
\hline \%Humedad & 6.87 & & \\
\hline
\end{tabular}

Los granos de cereales son matrices secas que se pueden considerar para el desarrollo de probiótico, ya que poseen fuente de carbono, nitrógeno, y minerales, macro y micronutrientes necesarios para el mantenimiento de los microorganismos probiótico en la matriz sólida. Según Andersson et al (2001), también son fuente de vitaminas y de fibra soluble como b-glucano y arabinoxilano), oligosacáridos como galacto-y fructooligosacáridos y almidón resistente, por lo que pueden actuar como prebiótico. El aporte en energía bruta fue de 103,06 Kcal/ por porción (21 g), Dependiendo de la composición de la barra de cereal será el aporte calórico de la misma, existe un amplio rango de variación en los niveles de energía que proporcionan las barras de cereal, se han reportado valores entre 110 y 154 kilocalorías $(25-30 \mathrm{~g})$ y 72,8 a 321,70 kcal. en $100 \mathrm{~g}^{-1}$ (Gutkoski et al, 2007; Dutcosky et al, 2006.)

Al ser incorporados probióticos a los cereales, se genera simbiosis, debido al carácter prebiótico de los cereales. Según Steed et al. (2008), productos en los que existen simultáneamente probióticos e ingredientes prebióticos se produce efecto sinérgico (El producto simbiótico también es relevante desde el punto de vista tecnológico, ya que la presencia de ingredientes prebióticos puede potencialmente mejorar el desempeño de los probióticos. Por otra parte, la industria está cada vez más interesada en el concepto simbiótico con el fin de explorar nuevos sectores del mercado y ampliar su gama de productos, que contribuyan a aumentar la competitividad en este campo.

\section{Estudio de Aceptabilidad Perfil de Sabor y Textura de la formulación D}

La aceptabilidad general de la formulación D se presenta en la Figura 2. La aceptabilidad general estuvo por encima del $50 \%$, exceptuando el olor que fue mayor de 70\%. El perfil de sabor (Figura 3), indica que los sabores que se percibieron con mayor intensidad fueron el arroz soplado, uvas pasas y el sabor dulce. No se percibieron sabores a rancio, o amargos. La percepción en cuanto a dureza, fracturabilidad, y adhesividad, de acuerdo a la escala establecida en todos los parámetros tuvo un valor promedio de 3 (fuerza media), un valor deseado para este tipo de producto. (Figura 4). Según De Paula et al., (2013), La percepción del consumidor es una interacción de las características inherentes al producto y la condición personal socio-económica, sicológica, fisiológica y cognitiva. Mediante medición instrumental Alvis et al. (2011), encontraron que la fuerza necesaria para fracturar tabletas de chocolate blanco es de 3678,2 Kpa.

\section{Viabilidad del probiótico incluido en la formulación $D$}

La tabla 3 presenta los promedios de los recuentos celulares de la bacteria probiótica desde el momento de obtención bajo fermentación, hasta la incorporación en la barra de cereal. Las diferencias de viabilidad entre los 4 momentos evaluados fueron estadísticamente significativas $(p<0.05)$. Las diferencias se encontraron en la liofilización y en la incorporación a la barra de cereal. 


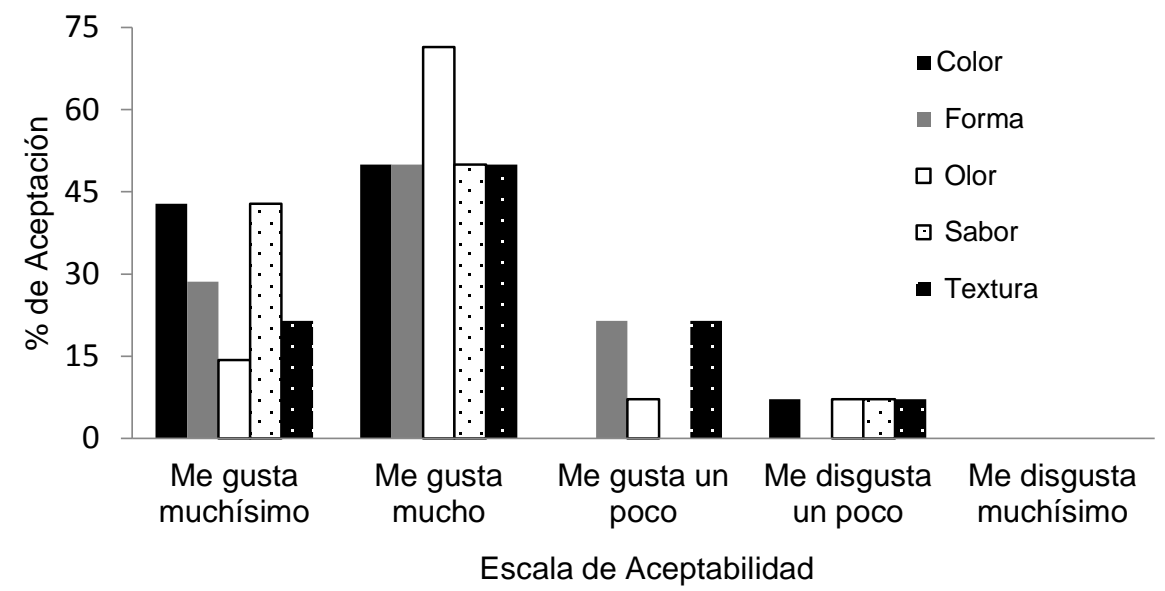

Fig. 2: Aceptabilidad general de la formulación

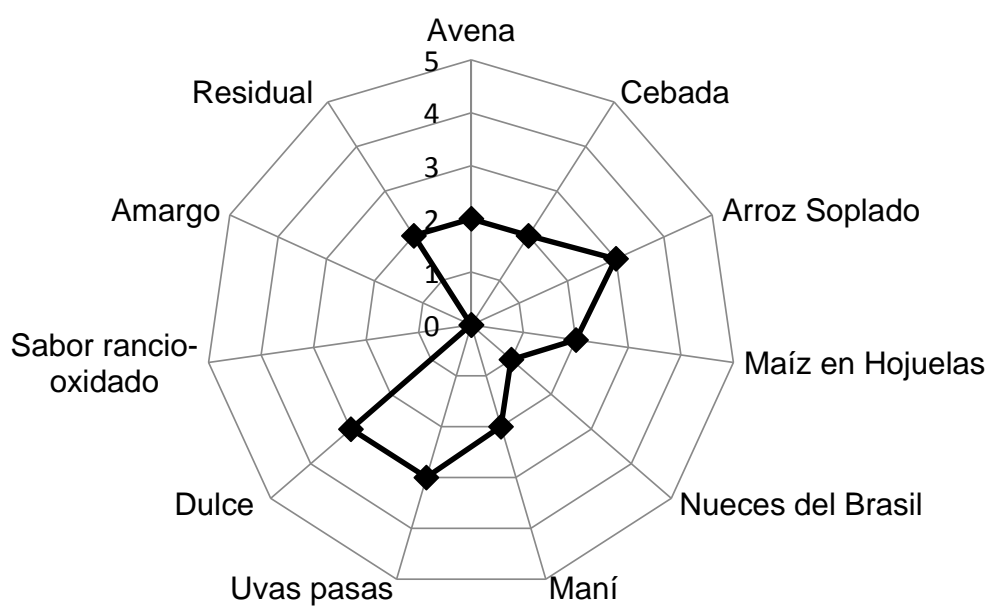

Fig. 3: Perfil de sabor de barras de cereal probiótico.

Tabla 3. Viabilidad del microorganismo probiótico (Weissella confusa), desde su reproducción hasta su uso como probiótico

\begin{tabular}{|l|l|}
\hline $\begin{array}{l}\text { Momento del proceso en el cual se midió la viabilidad del } \\
\text { microorganismo }\end{array}$ & $\begin{array}{l}\text { Viabilidad } \\
\text { UFC/(g) }(m l)\end{array}$ \\
\hline Concluida las fermentaciones & $3,73 \mathrm{E}+11$ \\
\hline Después del lavado con Na Cl 0.9\% & $3,35 \mathrm{E}+11$ \\
\hline Después de la liofilización & $6,11 \mathrm{E}+10$ \\
\hline Incorporada en la barra de cereal & $5,62 \mathrm{E}+07$ \\
\hline
\end{tabular}




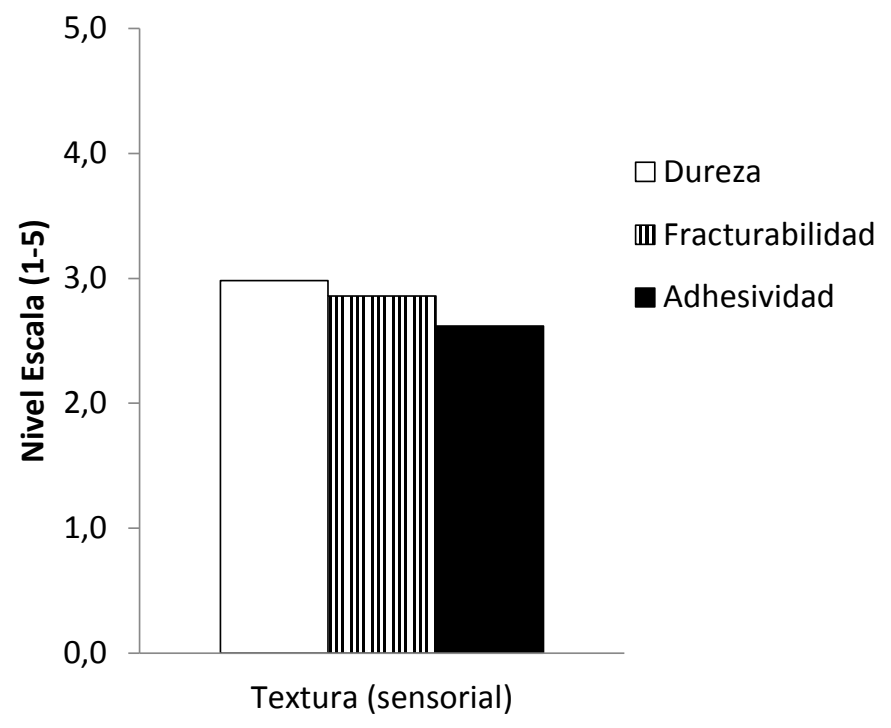

Fig. 4: Perfil de textura de barras de cereal probiótico.

Se presentaron diferencias estadísticamente significativas entre las viabilidades del probiótico en los cuatro momentos evaluados $(p<0.05)$. La pérdida de viabilidad durante la liofilización puede ser causada por las etapas de congelación, sublimación y secado. Cuando se liofilizan bacterias, algunas regiones de la membrana pueden verse afectados produciendo estrés celular. El estrés se produce porque los cristales de hielo rompen las membranas celulares, la ruptura es mayor cuando se utiliza congelación lenta, ya que se producen cristales de mayor tamaño. De igual manera la sublimación y el secado pueden ocasionar cambios en la permeabilidad de la membrana (Tripathi y Giri, 2014).

La pérdida de viabilidad ocasionada en el momento de incorporar las bacterias vehiculizadas en chocolate en la barra de cereal, se puede explicar por la concentración del medio vehiculizante, la cual ejerce presión osmótica sobre las membranas celulares de las bacterias, lo cual causa plasmólisis, además porque en el chocolate podría haber presencia de productos de peroxidación de lípidos, los cuales causan daño en el ADN de los microorganismos (Tripathi y Giri, 2014). Los resultados son contrarios a los obtenidos por Possemiers et al. (2010), quienes encontraron que el chocolate blanco protege a los microrganismos, obteniendo supervivencias mayores al 90\%. De igual manera, Do Espirito-Santo et al., (2011), indicaron que el recubrimiento de probióticos con chocolate es una solución excelente para protegerlos contra condiciones de estrés ambiental.

Aunque después del proceso de elaboración de las barras de cereal, el recuento de bacterias probióticas vivas fue superior a $10^{6}$, (límite para considerarse a un alimento probiótico), es importante señalar que este recuento se considera bajo, debido a que los microrganismos aún deben sobrevivir al almacenamiento, y a los jugos gástricos e intestinales del consumidor. Por lo anterior puede afirmarse que la incorporación de probióticos en matrices sólidas de humedad intermedia sigue siendo un desafío. Se deben intentar nuevas metodologías de incorporación de probióticos, como la encapsulación, con el fin de lograr una mejor protección de los microrganismos probióticos.

\section{CONCLUSIONES}

La excelente aceptabilidad y composición química de la barra de cereal desarrollada en esta investigación, hace que este producto sea adecuado para la incorporación de microorganismos probiótico, sin embargo el vehículo ideal para mantener vivas las bacterias probióticas en productos sólidos, es aún un desafío. La cobertura blanca es un vehículo que podría estudiarse con mayor detalle en investigaciones futuras para incorporar probióticos en matrices sólidas, debido a que el probiótico mantuvo su condición de probiótico durante todo el proceso de elaboración.

\section{REFERENCIAS}

Alvis, A., L. Perez y G. Arrazola, Determinación de las Propiedades de Textura de Tabletas de Chocolate Mediante Técnicas Instrumentales doi: 10.4067/S0718-07642011000300003, Información tecnológica: 22(3), 11-18 (2011). 
Andersson, H., N.G. Asp, A. Bruce, S. Roos, T. Wadstrom y A.E. Wold. Health effects of probiotics and prebiotics. A literature review on human studies, doi: 10.3402/fnr.v45i0.1790, Scandinavian Journal of Food and Nutrition: 45, 58-75. (2001).

AOAC 934.01 Official methods of analysis of the Association of Oficial Analytical Chemists 15 ed., Method 934.01. Virginia, usa. (1990)

AOAC 942.05. Official methods of analysis of the Association of Oficial Analytical Chemists. 15 ed., Arlington, Virginia, usa. Method 942.05. (1990).

AOAC 991.43. Official methods of analysis of the Association of Oficial Analytical Chemists international. Methods of analysis for nutrion labeling chapter method 991.43.dietary fiber. (Virginia) usa. (1993).

Charalampopoulos, D., R. Wang y S. Pandiella. Application of cereals and cereal components in functional foods: a review, doi: 10.1016/S0168-1605(02)00187-3, International Journal of Food Microbiology: 79, 131141. (2002).

De Man, J.C., M. Rogosa y M.E. Sharpe. A médium for the cultivation of lactobacilli, doi: 10.1111/j.13652672.1960.tb00188.x, Journal Applied Bacteriology: 23, 130-138 (1960).

De Paula,C.D, C.A., García, y A. M. Durango, Valor de la Marca en la Aceptación sensorial de consumidores en cuatro tipos de pan tajado blanco, doi: 10.4067/S0718-07642014000100013, Información tecnológica: 25(1), 127-132. (2014).

Do Espirito-Santo A. P., P. Perego, A. Converti y M.N. Oliveira. Influence of food matrices on probiotic viability e a review focusing on the fruity bases, doi: 10.1016/j.tifs.2011.04.008, Trends in Food Science \& Technology: 22, 377-385. (2011).

Dutcosky, S., M.V. Grossmann, R.S. Silva y A.K. Welsch. Combined sensory optimization of a prebiotic cereal product using multicomponent mixture experiments, doi: 10.1016/j.foodchem.2005.06.029, Food chemistry: 98, 630-638. (2006).

Elleuch, M., D. Bedigian y O. Roiseux, Dietary fibre and fibre-rich by-products of food processing: characterization, technological functionality and commercial applications: a review, doi: 10.1016/j.foodchem.2010.06.077, Food Chemistry: 124(2), 411-421. (2011).

European Commission. Regulation (ec) no 1924/2006 of the european parliament and of the council of 20 december 2006 on nutrition and health claims made on foods, Official journal of the European Union: 404, 9-25. (2006).

Fao/who (food and agriculture organization/word health organization): http://www.fao.org/fileadmin/templates/organicexports/docs/market_organic_ft_cocoa.pdf. Acceso: 13 de Marzo (2014.)

Ferreyra, V., A. Flores, M. Fournier, V. Aguilar, N. Apro, S. Giacomino, N. Pellegrino y M. Olivera. Estudio de la aceptabilidad en escolares de barras de cereales formuladas con ovoalbúmina, aceite de soja y miel, Diaeta, ISSN 1852-7337, (En línea): 27, 126 - 133. (2009). http://bases.bireme.br/cgibin/wxislind.exe/iah/online/?IsisScript=iah/iah.xis\&src=google\&base=LILACS\&lang=p\&nextAction=Ink\&exprS earch=520533\&indexSearch=ID. Acceso: 24 de 06 de 2014.

Freitas, D.Y. y R. Moretti. Caracterização e avaliação sensorial de barra de cereais funcional de alto teor proteico e vitamínico, doi:10.1590/S0101-20612006000200014, Ciência y Tecnología de Alimentos Campinas: 26(2), 318-324. (2006).

Funmilola, A., A. Sanchez, A. Abolanle, A. Margolles, G. Reyes - Gavilan y P. Ruas - Madiedo. Evaluation of the functional potential of weissella and lactobacillus isolates obtained from nigerian traditional fermented foods and cow's intestine, doi: 10.1016/j.ijfoodmicro.2011.03.014, International Journal of Food Microbiology: 147(2), 97-10. (2011). 
Gutkoski, I.C., J.M. Bonamigo, D.M. Teixeira and I. Pedó. Desenvolvimento de barras de cereais una base de aveia com alto teor de fibra alimentar, doi: 10.1590/S0101-20612007000200025, Ciência e Tecnologia de alimentos: 27(2), 355-363. (2007).

Jankovic, I., W. Sybesma, P. Phothirath, E. Ananta, y A. Mercenier. Application of probiotics in food products-challenges and new approaches, doi: 10.1016/j.copbio.2010.03.009 Current opinion in Biotechnology: 21,175-181. (2010).

Kjeldah, J. Neue methode zur bestimmung der stickstoffs in organischen korpern, doi: 10.1007/BF01338151, Journal of Analytical Chemistry: 22, 366-382. (1883).

Nawirska, A. Binding of heavy metals to pomace fibers, doi: 10.1016/j.foodchem.2004.04.009, Food Chemistry: 90(3), 395-400. (2005).

Olivera, M., V. Ferreyra, S. Giacomino, A. Curia, N. Pellegrino, M. Fournier y N. Apro. Desarrollo de barras de cereales nutritivas $y$ efecto del procesado en la calidad proteica, doi: 10.4067/S071775182012000300003, Revista Chilena de Nutrición: 39(3),18-25. (2012).

Ouwehand, A.C., T. Kurvinen y P. Rissanen. Use of a probiotic bifidobacterium in a dry food matrix, an in vivo study, doi: 10.1016/j.ijfoodmicro.2004.03.015, International Journal of Food Microbiology: 95, 103- 106 (2004.).

Possemiers, S., M. Marzorati, W. Verstraete y T. van de Wiele. Bacteria and chocolate: a successful combination for probiotic delivery, doi: 10.1016/j.ijfoodmicro.2010.03.008 International Journal of Food Microbiology: 141(24), 97-103. (2010).

Ranadheera, R.D.C.S., S.K. Baines y M.C. Adams. Importance of food in probiotic efficacy, doi: 10.1016/j.foodres.2009.09.009, Food research international: 43, 1-7. (2010).

Rivera - Espinoza, Y y Y. Gallardo - Navarro. Non-dairy probiotic products, doi: 10.1111/j.15414337.2010.00110.x, Food Microbiology: 27(1), 1-11. (2010).

Ryland D., M. Vaisey - Genser, S. Arntfield y I. Malcolmson. Development of a nutritious acceptable snack bar using micronized flaked lentils, doi: 10.1016/j.foodres.2009.07.032, Food Research International: 43, 642-649. (2010)

Sánchez - Tena, S. y otros ocho autores. Grape antioxidant dietary fiber inhibits intestinal polyposis in apcmin/+ mice: 32. Relation to cell cycle and immune response, doi: 10.1093/carcin/bgt140, Carcinogenesis: 8(34), 1881-1888. (2013).

Santivarangkna, C., U. Kulozik y P. Foerst. Effect of carbohydrates on the survival of lactobacillus helveticus during vacuum drying, doi: 10.1111/j.1472-765X.2005.01835.x, Letters in Applied Microbiology: 42, 271-276 (2006).

Serna, L., L. J. Valencia, R. Campos. Cinética de fermentación y acción antimicrobiana de Weissella confusa contra Staphylococcus aureus y Streptococcus agalactiae, Rev. Fac. Ing. Univ. Antioquia, ISSN 2145 - 2660, (En línea): 55, 55-65, (2010), http://www.scielo.org.co/pdf/rfiua/n55/n55a06. Acceso: 16 de 10 de 2014.

Serna, L., y C.E. Enríquez. Actividad antimicrobiana de weissella confusa y sus metabolitos frente a escherichia coli y klebsiella pneumoniae, doi: 10.15446/rev.colomb.biote.v15n2.34979, Revista Colombiana de Biotecnología: 15(2), 63-69. (2013).

Steed, H., G.T. Macfarlane, y S. Macfarlane. Prebiotics, synbiotics and inflammatory bowel disease, doi: 10.1002/mnfr.200700139, Molecular nutrition and food research: 52(8), 898-905 (2008).

Sun - Waterhouse, D., A. Teoh, C. Massarotto, R. Wibisono y S. Wadhwa. Comparative analysis of fruitbased functional snack bars, doi: 10.1007/s1194701 1-0563- 1, Food chemistry: 119, 1369-1379. (2010). 
Tripathi S.K,and M.K. Giri. Probiotic functional foods: survival of probiotics during processing and storage, doi: 10.1016/j.jff.2014.04.030, Journal of Functional Foods (en línea): 9, 225-241 (2014).

Van Soest P.J., J.B. Robertson y B.A. Lewis. Methods for dietary fiber, neutral detergent fiber and nonstarch polysaccharides in relation to animal nutrition, doi: 10.3168/jds.S0022-0302, (91)78551-2, Journal of Dairy Science: 74,3583-3597. (1991).

Vesterlund, S., K. Salminen y S. Salminen. Water activity in dry foods containing live probiotic bacteria should be carefully. Considered: a case study with lactobacillus rhamnosus gg in flaxseed, doi: 10.1016/j.ijfoodmicro.2012.05.016, International Journal of Food Microbiology: 157, 319-321. (2012). 
